\title{
Penerapan Metode Economic Order Quantity (EOQ) Untuk Meningkatkan Efisiensi Pengendalian Persediaan Bahan Baku Pada CV Syahdika
}

\author{
Ratningsih \\ Universitas Bina Sarana Informatika \\ e-mail: ratningsih.rnn@bsi.ac.id

\begin{tabular}{ccc}
\hline Diterima & Direvisi & Disetujui \\
$08-09-2021$ & $18-09-2021$ & $20-09-2021$ \\
\hline
\end{tabular}

\begin{abstract}
Abstrak - CV Syahdika merupakan perusahaan yang bergerak dalam bidang industri manufaktur yang memproduksi baju koko, dalam proses produksinya sangat berkaitan dengan persediaan bahan baku, CV Syahdika belum optimal dalam mengendalikan tingkat persediaan bahan bakunya karena kebijakan perusahaan masih menggunakan data data histori masa lalu, sehingga memerlukan suatu metode yang dapat mengoptimalkan pembelian bahan baku dan meminimalkan biaya persediannya, metode yang tepat dalam memecahkan masalah ini yaitu menggunakan metode Economic Order Quantity (EOQ). Tujuan penelitian ini untuk mengetahui pengendalian persediaan bahan baku CV Syahdika dengan membandingkan kebijakan pengelolaan persediaan yang berlaku sekarang di perusahaan dan menggunakan metode EOQ. Hasil dari penelitian ini bahwa pengendalian persediaan lebih efisien menggunakan metode EOQ, terbukti dapat melakukan penghematan dari faktor biaya yang harus dikeluarkan, dapat dilihat jumlah rata rata pembelian bahan baku sebanyak 3.550 yard setiap kali pesan dengan jumlah pemesanan 12 kali dalam setahun dan biaya persediannya sebesar RP. 8.408.333,345,- Sedangkan bila menggunakan metode EOQ jumlah pembeliannya sebanyak 15.713,24 yard dengan jumlah pemesanan 3 kali dalam setahun dan biaya persediannya sebesar RP. 3.614.784,84,- Berdasarkan metode EOQ perusahaan harus mengadakan safety stock sebesar 1.498 yard dan Re Order Point sebesar 1.420 yard untuk mengantisipasi keterlambatan bahan baku dan supaya bahan baku sesuai dengan lead time
\end{abstract}

Kata kunci: bahan baku, biaya pemesanan, biaya penyimpanan, metode EOQ, persediaan

\begin{abstract}
CV Syahdika is a company engaged in the manufacturing industry that produces koko clothes, in the production process is closely related to the supply of raw materials, CV Syahdika is not optimal in controlling the level of raw material inventories because the company policy still uses historical data, so it requires a method which can optimize the purchase of raw materials and minimize the cost of supplies, the right method in solving this problem is to use the Economic Order Quantity (EOQ) method. The purpose of this study was to determine the control of raw material inventory by $C V$ Syahdika by comparing the current inventory management policies in the company and using the EOQ method. The results of this study that inventory control is more efficient using the EOQ method, proven to be able to make savings from the cost factors that must be incurred, can be seen the average amount of raw material purchases of 3,550 yards per message with the number of orders 12 times a year and the supply costs of Rp. . 8,408,333,345, - whereas when using the EOQ method the purchase amount is 15. 713.24 yards with the number of orders 3 times a year and the supply costs are Rp. 3,614,784.84, - Based on the EOQ method the company must hold a safety stock of 1,498 yards and a Re Order Point of 1,420 yards to anticipate delays in raw materials and so that raw materials are in accordance with lead time.
\end{abstract}

Keywords: EOQ method, inventory, ordering costs, raw materials, storage costs

\section{PENDAHULUAN}

Pada perusahaan yang bergerak di bidang manufaktur baik itu perusahaan yang berskala kecil, sedang ataupun besar di dalam menjalankan kegiatan bisnisnya harus menghasilkan produk yang memiliki kualitas yang baik yang dapat memenuhi keinginan dan kebutuhan para pembeli atau konsumen sehingga konsumen merasa mendapat tingkat kepuasan yang maksimal atas penggunaan produk perusahaan tersebut. Dalam proses produksi, perusahaan membutuhkan bahan baku untuk menghasilkan produknya. Bahan baku adalah sesuatu yang digunakan untuk membuat barang jadi (Nanda, 2015) Bahan pasti menempel menjadi satu dengan barang jadi. Dalam sebuah perusahaan, bahan baku dan bahan penolong memiliki arti yang sangat penting karena menjadi modal terjadinya proses produksi sampai hasil produksi. Berdasarkan hal demikian maka perusahaan khususnya di bagian produksi harus memperhatikan mengenai masalah persediaan bahan bakunya. Persediaan adalah barang barang yang 
disimpan untuk digunakan atau dijual pada masa atau periode yang akan datang (Abdul and Albasit, 2019). Sistem dalam pengelolaan persediaan merupakan serangkaian kebijakan pengendalian untuk menentukan tingkat persediaan yang harus dijaga.

CV Syahdika merupakan perusahaan yang berdiri pada tahun 2006 yang bergerak di bidang usaha manufaktur yang memproduksi barang jadi berupa baju koko.Di dalam menjalankan kegiatan proses produksinya CV Syahdika di dalam melakukan pembelian bahan baku produknya atau dalam mengelola tingkat persediaan bahan bakunya masih menggunakan data data histori masa lalu atau berdasarkan pengalaman dilapangan saja tidak menggunakan metode metode khusus sehingga adakalanya di temui kendala atau masalah yang muncul seperti terjadi ketidakstabilan dalam mengelola tingkat persediaan bahan bakunya seperti terkadang perusahaan membeli bahan baku dengan jumlah yang sangat banyak dan menimbun stok persediaan digudang dengan alasan supaya mendapatkan diskon jika pembelian bahan baku dalam jumlah banyak tanpa memperhatikan masalah apa yang akan muncul di masa yang akan datang sehingga mengakibatkan tingginya jumlah biaya yang harus dikeluarkan dalam hal biaya penyimpanan atau biaya pemeliharaannya sehingga di rasa tidak efektif terjadi sejumlah pemborosan biaya biaya yang harus dikeluarkan, atau terkadang juga sebaliknya pernah terjadi masalah minimnya stok persedian di gudang sehingga mengakibatkan terhambatnya proses produksi yang mengakibatkan turunnya tingkat penjualan yang diperoleh perusahaan.

Berdasarkan hal tersebut CV syahdika masih belum optimal di dalam melakukan pengendalian persediaan bahan bakunya sehingga perlu dibantu dengan metode khusus agar tingkat pemesanan optimal dengan meminimalkan biaya persediaan atau biaya pembeliannya yaitu menggunakan metode Economic Order Quantity (EOQ) sehingga dengan metode ini CV Syahdika bisa lebih mengoptimalkan lagi pengendalian persediaannya. Oleh karena itu maka penulis merasa tertarik untuk meneliti mengenai penerapan metode Economic Order Quantity (EOQ) untuk meningkatkan efisiensi pengendalian persediaan bahan baku pada CV Syahdika. (Batennia et al., 2019) “ persediaan dapat diartikan sebagai barang-barang yang disimpan untuk digunakan atau dijual pada masa atau periode yang akan datang". (Sejati et al., 2016) "persediaan adalah suatu persediaan aktiva yang meliputi barang-barang milik perusahaan dengan maksud dijual dalam suatu periode usaha yang normal, atau persediaan barangbarang yang masih dalam proses produksi, ataupun persediaan bahan baku yang masih menunggu untuk digunakan dalam suatu proses produksi.

Berdasarkan pengertian persediaan menurut para ahli seperti yang disebut diatas, maka penulis dapat menyimpulkan bahwa persediaan merupakan sejumlah bahan-bahan yang disediakan berupa bahan baku serta bahan-bahan dalam proses untuk proses produksi yang terdapat dalam perusahaan untuk memenuhi permintaan dari konsumen setiap waktu.

a. Biaya-Biaya Dalam Persediaan

Biaya dalam sistem persediaan secara umum dapat diklasifikasikan sebagai berikut:

1) Biaya Pembelian (Purchasing Cost)

Biaya pembelian (purchase cost) dari suatu item adalah harga pembelian setiap unit item jika item tersebut berasal dari sumber-sumber eksternal, atau biaya produksi per unit bila item tersebut berasal dari internal perusahaan atau diproduksi sendiri oleh perusahaan.

2) Biaya Pengadaan (Procurement Cost)

Biaya pengadaan dibedakan atas 2 jenis sesuai asal-usul barang,.

a) Pemesanan (Ordering Cost)

Biaya Biaya pemesanan adalah semua pengeluaran yang timbul untuk mendatangkan barang dari luar.

b) Biaya Pembuatan (Set up Cost)

Ongkos pembuatan adalah semua pengeluaran yang ditimbulkan untuk persiapan memproduksi barang.

3) Biaya Penyimpanan (Holding Cost)

Biaya penyimpanan (holding cost) merupakan biaya yang timbul akibat disimpannya suatu item

4) Biaya Kekurangan Persediaan (Shortage Cost) Dari semua biaya-biaya yang berhubungan dengan tingkat persediaan, biaya kekurangan bahan (stockout cost) adalah yang paling sulit diperkirakan. Biaya ini timbul bilamana persediaan tidak mencukupi permintaan produk atau kebutuhan bahan.

Berikut dibawah ini beberapa penelitian terdahulu Penelitian mengenai Analisis Efisiensi Biaya Persediaan menggunakan metode EOQ (Economic Order Quantity) Pada PT. XYZ (Umami et al., 2018) membahas tentang suatu alat atau teknik yg di gunakan oleh manajemen untuk mengetahui tingkat persediaan bahan baku digudang dengan membuat perencanaan persediaan untuk memenuhi pesanan pembeli dan untuk menghindari adanya persediaan berlebih yang menyebabkan penggunaan dana menjadi tidak efisien.Metode yang digunakan yaitu metode Economic Order Quantity (EOQ) yaitu suatu metode yang digunakan untuk melakukan pembelian dalam jumlah optimal serta untuk mengurangi biaya persediaan. Dengan metode EOQ ini dapat dicari pula mengenai ReOrder Point (ROP), Maximum Inventory dan Safety stock. Tujuan dari penelitian ini adalah untuk mendeskripsikan mengenai penerapan Metode EOQ (Economic Order Quantity)dalam mendeskripsikan gambaran perencanaan persediaan untuk melakukan pembelian optimal dengan biaya persediaan minimum yang dikeluarkan oleh perusahaan. 
Kemudian penelitian mengenai Analisis Pengendalian Persediaan Bahan Baku Kayu Cempaka Pada Industri mebel dengan Menggunakan Metode EOQ (Studi Kasus Pada UD. Batu Zaman) (Simbar1 et al., 2014) membahas tentang volume bahan baku kayu cempaka optimal yang dibutuhkan oleh UD. Batu Zaman untuk periode tahun 2013. Metode yang digunakan dalam analisis adalah metode Economic Order Quantity (EOQ) yaitu suatu metode atau alat yang digunakan untuk mengetahui kuantitas pembelian optimal dengan penggunaan biaya persediaan minimum, Dengan metode EOQ ini dapat dicari mengenai pengendalian persediaan dari segi total biaya persediaan, Safety Stock dan $R e$ Order Point (ROP). Selanjutnya penelitian

\section{METODE PENELITIAN}

Penelitian yang dilakukan merupakan penelitian komparatif. Adapun subjek dari penelitian ini adalah CV Syahdika yang berlokasi di Jalan Perintis Kemerdekaan, Kawalu,Kersamenak, Tasikmalaya. Jenis data yang digunakan dalam penelitian adalah kebutuhan bahan baku pertahun, biaya pemesanan, biaya persediaan. Ada beberapa variable analisis perhitungan untuk mendukung penggunaan metode EOQ yaitu sebagai berikut:

Metode yang digunakan adalah Metode Economic

Order Quantity (EOQ)

a) Economic order Quantity

EOQ merupakan nilai jumlah bahan yang dibutuhkan selama setiap kali pembelian dengan menggunakan biaya paling ekonomis.

Rumus yang digunakan dalam menghitung EOQ adalah :

$$
E O Q=\sqrt{\frac{2 S D}{H}}
$$

Dimana :

D : Jumlah kebutuhan bahan baku per tahun

$\mathrm{S}$ : Biaya pemesanan sekali pesan

$\mathrm{H}$ : Biaya penyimpanan per unit

b) Total Inventory Cost (TIC)

Total inventory cost merupakan perhitungan total persediaan bahan baku yang digunakan untuk mengetahui apakah perhitungan pembelian persediaan menggunakan metode EOQ lebih baik dibandingkan dengan metode konvensional perusahaan.

Rumus yang digunakan untuk menghitung TIC adalah :

$\mathrm{TIC}=$

$\left[\frac{D}{Q} S\right]+\left[\frac{Q}{2} H\right]$

Dimana :

D : jumlah kebutuhan bahan baku

$\mathrm{S}$ : Biaya pemesanan

$\mathrm{H}$ : Biaya penyimpanan per unit

Q : Pembelian bahan baku yang ekonomis

c) Safety Stock
PenerapanMetode Economic Order Quantity (EOQ) Untuk Meningkatkan

Efisiensi Biaya Persediaan Bahan Baku (Studi Kasus pada PT Nusamulti Centralestari) (Palupi et al., 2018) Membahas tentang perbandingan perhitungan biaya persediaan dengan menggunakan kebijakan perusahaan dan menggunakan metode Economic Order Quantity (EOQ) lebih efisien mana hasil perhitungan mengenai biaya persediaan yang harus dikeluarkan oleh perusahaan. Metode yang digunakan dalam penelitian ini adalah menggunakan metode Economic Order Quantity (EOQ) suatu metode didalam melakukan pembelian sejumlah bahan baku secara optimal dengan mengurangi biaya persediaan yang harus dikeluarkan oleh perusahaan Safety stock merupakan metode yang berguna untuk melindungi perusahaan dari segala resiko yang dapat ditimbulkan dari adanya persediaan. Perhitungan safety stock didasarkan pada seberapa besar nilai penyimpangan yang terjadi terhadap rata-rata selama periode beberapa bulan terakhir. Nilai penyimpangan adalah standart deviasi yang dihitung dengan menggunakan rumus sebagai berikut: $S_{d}=\sqrt{\frac{\sum(x-\bar{x})^{2}}{n}}$ (3)

Dimana :

$\mathrm{n}$ : jumlah pemesanan bahan baku

$x$ : jumlah kebutuhan bahan baku

$\bar{x}$ : rata-rata kebutuhan bahan baku

Dari hasil standart deviasi tersebut dapat diketahui safety stock dengan menggunakan rumus berikut:

Safety Stock $=S_{d} \times Z$ (4)

Dimana :

$S_{d}:$ Standart Deviasi

$\mathrm{Z}$ : Faktor pengaman

d) Re Order Point (ROP)

Re Order Point (ROP) digunakan untuk memonitor barang persediaan, sehingga pada saat melakukan pemesanan barang kembali barang yang dipesan akan datang tepat waktu.

Sebelum menghitung ROP maka terlebih dahulu dicari tingkat penggunaan bahan baku per hari (d) dengan rumus sebagai berikut: $d=\frac{D}{t}$ (5)

d= Jumlah Kebutuhan bahan baku perhari

$\mathrm{D}=$ Total Kebutuhan bahan baku

$\mathrm{t}=$ total jumlah kerja per tahun

Rumus yang digunakan untuk menghitung ROP adalah:

Reorder point $=\mathrm{d} \times \mathrm{L}(6)$

Dimana :

$\mathrm{d}=$ Jumlah Kebutuhan bahan baku perhari

$\mathrm{L}=$ Lead time (waktu tunggu)

Sumber data yang digunakan dalam penelitian ini adalah data primer berupa hasil wawancara dengan manager bagian produksi yang dilaksanakan oleh $\mathrm{Cv}$ Syahdika serta data persediaan bahan baku yang diperoleh dari dokumen bagian produksi mengenai bahan bahan yang dipergunakan dalam membuat 
produk baju koko. Adapun teknik analisis data yang digunakan dalam penelitian ini adalah teknik analisis kuantitatif dengan pendekatan komparatif yang dipergunakan untuk membahas mengenai perbandingan penentuan persediaan bahan baku yang diterapkan CV Syahdika dan penentuan persediaan bahan baku dengan menggunakan metode Economic Order Quantity (EOQ).

\section{HASIL DAN PEMBAHASAN}

Bahan baku yang digunakan oleh CV Syahdika dalam memproduksi baju koko tersebut menggunakan bahan baku utama nya yaitu jenis kain oxpord yang didatangkan dari supplier bernama PT. Dunia Tex yang berlokasi di solo, frekuensi pemesanan bahan baku kain oxpord ini dilakukan satu bulan satu kali dengan waktu tunggu pesan sekitar kurang lebih 10 hari. Kain oxpord yang digunakan oleh CV Syahdika pada tahun 2018 jika di perkirakan kurang lebih menghabisan 42.600 yard dengan harga per yard nya yaitu kurang lebih sebesar Rp. 18.000,-Sedangkan untuk bahan baku pelengkap yang digunakan oleh CV Syahdika yaitu ada yang namanya benang dan untuk benang tersebut ada 2 macam yaitu benang bordir dan benang jahit yang didatangkan dari supplier yang bernama Srikandi yang berlokasi di Tasikmalaya , untuk benang bordir biasanya CV Syahdika melakukan pembelian selama setahun kurang lebih sebesar 6000 cones dengan harga/cones yaitu sebesar Rp. 7.800,-, sedangkan untuk pembelian benang jahit dalam setahun CV Syahdika kurang lebih melakukan pembelian sebanyak 8000 cones dengan harga benang jahit/cones sebesar Rp. 1.750/cones, ada satu lagi bahan baku penolong selain benang tersebut yaitu berupa kain keras dimana CV Syahdika melakukan pemesanan atau pembelian ke supplier yang berlokasi di bandung, dalam satu tahun kurang lebih CV syahdika melakukan pembelian sebanyak 40 rol dengan harga /roli yaitu sebesar Rp. 350.000,-

Untuk lebih jelasnya bisa kita lihat [ada tabel dibawah ini :

Tabel 1. Data Bahan Baku CV Syahdika

\begin{tabular}{ll}
\hline Kain Oxpord & 42600 Yard \\
\hline Benang Jahit & 8000 cones \\
\hline Benanr Bordir & 6000 cones \\
\hline Kain keras & 40 roll \\
\hline Sumber ; (CV Syahdika, 2018)
\end{tabular}

Adapun jenis produk jadi yang dihasilkan oleh CV Syahdika berupa baju koko dengan memiliki 3 kode jenis baju koko yaitu KDN, SKT dan SPD.dimana permintaan pemesanan baju koko ini akan meningkat jika mendekati hari raya idul fitri yaitu kurang lebih mengalami kenaikan permintaan atau pemesanan sebanyak 30\%. Dalam hal ini kita akan memfokuskan membahas mengenai pengendalian persediaan bahan baku utama yaitu kain oxford yang secara keseluruhan mempengaruhi proses produksi baju koko tersebut.terkadang masalah yang sering dihadapi oleh CV Syahdika adalah waktu tunggu yang lama sehingga perlu melakukan pembelian yang seoptimal mungkin guna meminimalkan biaya persediaan, supaya proses produksi tetap berjalan lancar. Untuk stok aman di gudang CV Syahdika tidak menghabiskan langsung bahan baku dalam satu kali perputaran proses produksi hal ini dilakukan untuk mengantisipasi jika ada permintaan dadakan atau musiman sehingga bahan baku perlu di cadangkan, CV Syahdika biasanya membuat cadangan persediaan yang tidak dapat ditentukan dan biasanya menggunakan data histori masa lalu saja. Untuk jumlah produksi dalam satu hari menghasilkan produk jadi antara $4000 \mathrm{pcs}$, 3800 pcs, 3700 pcs, namun jika sedang sepi permintaan maka jumlah produksi sehari sebanyak 2500 pcs. Berikut Data kebutuhan bahan baku kain oxpord tahun 2018 (Yard)

Tabel 2. Data Kebutuhan Bahan Baku Tahun 2018

\begin{tabular}{lll}
\hline NO & Bulan Pembelian & Jumlah Kain (Yard) \\
\hline 1 & Januari & 3100 \\
\hline 2 & Februari & 3000 \\
\hline 3 & Maret & 3000 \\
\hline 4 & April & 3200 \\
\hline 5 & Mei & 3200 \\
\hline 6 & Juni & 6300 \\
\hline 7 & Juli & 2800 \\
\hline 8 & Agustus & 4000 \\
\hline 9 & September & 3000 \\
\hline 10 & Oktober & 3500 \\
\hline 11 & November & 3500 \\
\hline 12 & Desember & 4000 \\
\hline Jumlah & 42.600 \\
\hline
\end{tabular}

Sumber (CV Syahdika, 2018)

Berdasarkan Tabel 2 diatas dapat disimpulkan bahwa pembelian bahan baku kain oxford selama tahun 2018 adalah sebesar 42600 yard. dengan frekuensi pemesanan satu bulan satu kali pemesanan jadi jika dalam waktu setahun frekuensi pemesanan bahan baku ke pemasok sebanyak 12 kali.Dari tabel diatas dapat kita lihat bahwa pembelian bahan baku pada setiap bulannya selalu berfluktuasi kadang meningkat dan kadang menurun tingkat pembeliannya, hal ini disebabkan karena dipengaruhi oleh permintaan konsumen yang tidak menentu, jumlah pembelian bahan baku tertinggi terjadi pada bulan Juni karena adanya hari idul fitri sehingga jumlah permintaan konsumen meningkat 30\% dan juga secara otomatis jumlah pembelian bahan baku pun tinggi yaitu sebanyak 6300 yard. Dapat kita lihat juga pada bulan juli jumlah pembelian bahan baku berada dalam tingkat pembelian terendah sebesar 2800 yard, dikarenakan jumlah permintaan menurun setelah perayaan idul fitri sehingga jumlah produksi pun dikurangi juga.
3.1.Perhitungan Total InventoryCost (TIC) Menurut Perusahaan dan Metode EOQ
a. Biaya Pemesanan (Ordering Cost) 
Biaya pemesanan adalah semua pengeluaran yang timbul untuk mendatangkan barang dari luar. Untuk biaya pemesanan CV syahdika dapat kita lihat pada tabel dibawah ini:

Tabel 3. Data Biaya Pemesanan Kain Oxford

\begin{tabular}{lll}
\hline NO & Jenis Biaya & Jumlah (Rp) \\
\hline 1 & Biaya Telepon & Rp. 400.000,- \\
\hline 2 & $\begin{array}{l}\text { Biaya Transportasi } \\
\text { Pembongkaran }\end{array}$ & Rp. $7.000 .000,-$ \\
\hline 3 & Biaya Administrasi & Rp. $600.000,-$ \\
\hline & Jumlah & Rp. $8.000 .000,-$
\end{tabular}

Sumber : Data Primer yang di olah

Berdasarkan tabel diatas bahwa jumlah keseluruhan untuk biaya pemesanan CV Syahdika tahun 2018 adalah sebesar Rp. 8.000.000,-

b. Biaya Penyimpanan (Carrying Cost) atau ( Holding Cost)

Biaya Penyimpanan adalah biaya yang timbul karena disimpannya suatu item. Untuk biaya penyimpanan CV Syahdika dapat dilihat pada tabel dibawah ini

Tabel 4. Data Biaya Penyimpanan Kain Oxford

\begin{tabular}{lll}
\hline No & Jenis Biaya & Jumlah (Rp) \\
\hline 1 & Biaya Listrik Gudang & Rp. 800.000,- \\
\hline 2 & Biaya Buruh Gudang & Rp. 4.000.000,- \\
\hline 3 & $\begin{array}{l}\text { Biaya Cadangan } \\
\text { Rusak }\end{array}$ & Rp. 5.000.000,- \\
\hline Jumlah & Rp. 9.800.000,- \\
\hline
\end{tabular}

Berdasarkan tabel diatas bahwa jumlah keseluruhan untuk biaya penyimpanan CV Syahdika tahun 2018 adalah sebesar Rp. 9.8.00.000,-

Perhitungan Biaya Pesan dan Biaya Simpan

1) Biaya Pemesanan setiap kali pesan (S)

$S=\frac{R p .8000 .000,-}{12} S=\frac{\text { total biaya pesan }}{\text { frekuensi pemesanan }}$

$\mathrm{S}=$ Rp. 666.666,66,-

2) Biaya penyimpanan persatuan bahan baku $(\mathrm{H})$

$$
\begin{gathered}
H=\frac{\text { total biaya simpan }}{\text { total kebutuhan bahan baku }} \\
H=\frac{\text { Rp.9.800.000 }}{42.600} \\
H=230.047 \text { Yard }
\end{gathered}
$$

c. Kebijakan Perusahaan

CV Syahdika menggunakan bahan bakunya jenis kain oxford yang didatangkan dari supplier bernama PT Dunia Tex yang berlokasi di Solo, dimana CV syahdika melakukan pemesanan untuk bahan bakunya sebanyak 12 kali dalam setahun.

1) Perhitungan Pembelian Bahan Baku (Q)

Kita akan melakukan perhitungan untuk pembelian bahan baku kain oxford (Q) berdasarkan kebijakan perusahaan yang melakukan pemesanan sebulan sekali.Perhitungannya dapat kita lihat seperti dibawah ini :

$Q=\frac{42.600}{12} Q=\frac{\text { total kebutuhan bahan baku }}{\text { frekuensi pemesanan }}$
$Q=3550$ yard

Berdasarkan perhitungan di atas maka dapat disimpulkan jumlah pembelian bahan baku pada $\mathrm{CV}$
Syahdika dalam sekali pemesanan adalah sebesar 3.550 yard

2) Total Biaya Persediaan

Untuk melakukan perhitungan total biaya persediaan maka diketahui :

- Total Kebutuhan bahan baku (D) = 42.600 Yard

- Pembelian Rata-rata bahan baku (Q) = 3550 Yard

- Biaya pemesanan sekali pesan $(\mathrm{S}) \quad=\quad \mathrm{Rp}$. 666.666,66,-

- Biaya simpan per Yard

230,047/Yard

$=\mathrm{Rp}$.

$T I C=\left[\frac{42.600}{3.550} 666.666,66\right]+\left[\frac{3550}{2} 230,047\right]\left[\frac{D}{Q} S\right]+$ $\left[\frac{Q}{2} H\right]$ (10)

Maka Total biaya persediaan dapat dihitung sebagai berikut :

$\mathrm{TIC}=$

$T I C=7.999 .999,92+408.333,425$

TIC $=8.408 .333,345$

Jadi total biaya persediaan yang harus ditanggung oleh CV Syahdika adalah Rp. 8.408.333,345,-

d. Metode Economic Order Quantity (EOQ) Adapun sejumlah data yang digunakan untuk melakukan perhitungan metode EOQ adalah sebagai berikut :

1) Pembelian bahan baku yang ekonomis :

- Total Kebutuhan bahan baku (D) = 42.600 Yard

- Biaya pemesanan sekali pesan $(S)=R p$. 666.666,66,-

- Biaya simpan per $\operatorname{Yard}(\mathrm{H})=$ Rp. 230,047,-

Maka dapat kita hitung pembelian paling ekonomisnya sebagai berikut :

$E O Q=15.713,24$ YardEOQ $=$

$\sqrt{\frac{2 \times 42.600 \times 666.666,66}{230,047}} E O Q=\sqrt{\frac{2 S D}{H}}$

Jadi jumlah pembelian bahan baku ekonomis memggunakan metode EOQ adalah sebesar 15.713 Yard

2) Frekuensi Pemesanan Bahan Baku $F=\frac{42.600}{15.713,24} F=\frac{D}{E O Q}$ (13)

Dengan menggunakan metode EOQ maka dapat kita hitung jumlah frekuensi pemesanan dalam satu tahun atau disebut juga frekuensi pembelian sebagai berikut :

$F=2,7=3 x$

Maka kita bisa mengetahui dengan menggunakan metode EOQ Frekuensi pembelian dalam setahun sebanyak $3 \mathrm{x}$ 
3) Total biaya persediaan

Untuk menghitung total biaya persediaan menurut metode EOQ maka ada sejumlah data yang dibutuhkan adalah sebagai berikut :

- Total kebutuhan bahan baku (D) = 42.600 Yard

- Biaya pemesanan sekali pesan $(\mathrm{S})=\mathrm{Rp}$. 666.666,66,-

- $\quad$ Biaya simpan per $\operatorname{Yard}(\mathrm{H})=$ Rp. 230,047,-

- $\quad T I C=\left[\frac{D}{Q} S\right]+\left[\frac{Q}{2} H\right](14)$

Pembelian bahan baku paling ekonomis $(\mathrm{Q})=$ 15.713,24 Yard

$T I C=\left[\frac{42.600}{15.713,24} 666.666,66\right]+\left[\frac{15.713,24}{2} 230,047\right]$

(15)

$T I C=1.807 .392,98+1.807 .391,86$

TIC $=3.614 .784,84$

Jadi total persediaan bahan baku CV Syahdika bila menggunakan metode EOQ adalah sebesar Rp. 3. $614.784,84,-$

4) Penentuan persediaan Pengaman (Safety Stock) Persediaan pengaman atau safety stock dalam suatu perusahaan sangat penting sekali karena akan memperlancar proses produksi jika ada permintaan produksi dadakan atau yang bersifat musiman, hal ini untuk mengantisipasi jika adanya keterlambatan Berdasarkan tabel diatas maka kita akan melakukan perhitungan standar deviasinya :

$S_{d}=907,83 S_{d}=\sqrt{\frac{9.890 .000}{12}} S_{d}=\sqrt{\frac{\sum(x-\bar{x})^{2}}{n}}$

Dengan menggunakan perkiraan atau asumsi bahwa perusahaan memenuhi permintaan Sebanyak 95\% dan persediaan cadangan sebesar $5 \%$, maka diperoleh $\mathrm{Z}$ dengan tabel normal sebesar 1,65 standar deviasi dari rata-rata :

$=1,65 \times 907,83$

$=1.497,92$ jika dibulatkan adalah 1.498 Yard

Maka persediaan pengaman yang harus disediakan oleh CV Syahdika adalah sebesar 1.498 Yard

5) Titik Pemesanan Kembali (Re Order Point)

CV Syahdika dalam melakukan pemesanan bahan baku kain oxford memiliki waktu tunggu pemesanan sampai bahan baku tiba selama 10 hari $(\mathrm{L})=10$ hari, dengan rata rata waktu bekerja dalam setahun rata rata 300 hari, maka sebelum menghitung ROP terlebih dahulu dicari tingkat penggunaan bahan baku dengan cara sebagai berikut :

$=142 d=\frac{42.600}{300} d=\frac{D}{t}(18)$

Maka ROP $=\mathrm{d} \times \mathrm{L}$

Dari tabel ditas dapat kita lihat bahwa biaya yang dikeluarkan Perusahaan adalah sebesar Rp 8.408.333,345,-. Sedangakan total biaya persediaan yang dikeluarkan perusahaan bila menggunakan metode EOQ adalah sebesar Rp 3.614.784,84,- dapat diketahui penghematannya sebesar Rp 4.793.548,505,-, hal ini dapat terlihat jelas jika CV datangnya bahan baku yang dipesan sehingga bisa menyebabkan pelaksanaan proses produksi menjadi terhambat atau terhenti. Dalam menghitung safety stock digunakan metode statistik dengan membandingkan rata-rata bahan baku dengan pemakaian bahan baku yang sesungguhnya kemudian dicari penyimpangannya.

Perhitungan standar deviasi dapat dilihat pada tabel berikut:

Tabel 5 Data Perhitungan Standar Deviasi

\begin{tabular}{lllll}
\hline Bulan & $\begin{array}{l}\text { Jumlah } \\
\text { bahan } \\
\text { baku }\end{array}$ & $\mathrm{X}$ & $(\mathrm{X}-\mathrm{X})$ & $(\mathrm{X}-\mathrm{X})^{2}$ \\
\hline Januari & 3100 & 3550 & -450 & 202.500 \\
\hline Februari & 3000 & 3550 & -550 & 302.500 \\
\hline Maret & 3000 & 3550 & -550 & 302.500 \\
\hline April & 3200 & 3550 & -350 & 122.500 \\
\hline Mei & 3200 & 3550 & -350 & 122.500 \\
\hline Juni & 6300 & 3550 & 2750 & 7.562 .500 \\
\hline Juli & 2800 & 3550 & -750 & 562.500 \\
\hline Agustus & 4000 & 3550 & 450 & 202.500 \\
\hline September & 3000 & 3550 & -550 & 302.500 \\
\hline Oktober & 3500 & 3550 & -50 & 2500 \\
\hline November & 3500 & 3550 & -50 & 2500 \\
\hline Desember & 4000 & 3550 & 450 & 202.500 \\
\hline & & & Jumlah & 9.890 .000 \\
\hline Sumber: Da yang diah, 2018 &
\end{tabular}

Sumber : Data yang diolah, 2018

$=142 \times 10$

$=1420$ Yard

Maka CV Syahdika harus melakukan pemesanan bahan baku kain oxford pada tingkat jumlah sebesar 1420 Yard.

6) Perbandingan Kebijakan perusahaan dengan metode EOQ

Dari hasil perhitungan dan analisa di atas maka telah diketahui perbandingan antara total biaya yang dikeluarkan perusahaan dan kebijakan menggunakan metode EOQ seperti yang dapat kita lihat pada tabel di bawah ini :

Tabel 6. Perbandingan kebijakan perusahaan dan Metode EOQ

\begin{tabular}{clll}
\hline No & Keterangan & $\begin{array}{l}\text { Kebijakan } \\
\text { Perusahaan }\end{array}$ & Metode EOQ \\
\hline 1 & $\begin{array}{l}\text { Pembelian rata- } \\
\text { rata bahan baku }\end{array}$ & 3.550 yard & $15.713,24$ yard \\
\hline 2 & $\begin{array}{l}\text { Total Biaya } \\
\text { persediaan }\end{array}$ & Rp.8.408.333,345,- & Rp.3.614.784,84,- \\
\hline 3 & $\begin{array}{l}\text { Frekuensi } \\
\text { Pemesanan }\end{array}$ & $12 \mathrm{x}$ \\
\hline 4 & Safety Stock & - & 1.498 yard \\
\hline 5 & Re Order Point & - & 1.420 yard \\
\hline
\end{tabular}

Sumber : Data Primer yang di olah, 2018

Syahdika melakukan pemesanan atau pembelian bahan baku dengan menggunakan metode EOQ, maka $\mathrm{Cv}$ Syahdika bisa melakukan pembelian seoptimal mungkin sehingga bisa meminimalkan biaya persediannya, hal ini bisa menghemat atau memangkas biaya biaya yang harus dikeluarkan di 
dalam proses produksi guna mendapatkan tingkat keuntungan yang semaksimal mungkin.

\section{KESIMPULAN}

Dari hasil penelitian yang telah penulis lakukan, maka dapat di ambil kesimpulan dari penelitian ini adalah Frekuensi pembelian bahan baku kain oxford Pada CV Syahdika bila menggunakan metode EOQ adalah sebanyak 3 kali pembelian bahan baku dalam satu tahun, sedangkan jika berdasarkan kebijakan perusahaan, frekuensi pemesanan bahan baku nya sebanyak 12 kali dalam satu tahun. Total biaya persediaan bahan baku perusahaan bila dihitung menurut metode EOQ adalah sebesar Rp. 3.614.784,84,- sedangkan bila dihitung berdasarkan kebijakan perusahaanadalah sebesar Rp. 8.408.333,345,-. Terdapat pemangkasan biaya persediaan yang harus dikeluarkan oleh $\mathrm{CV}$ Syahdika bila menggunakan metode EOQ adalah sebesar Rp. 4.793.548,505,-. CV Syahdika dalam kebijakannya tidak menetapkan adanya persediaan pengaman (Safety Stock) ,sedangkan berdasarkan metode EOQ, perusahaan harus mengadakan Safety Stock untuk memperlancar proses produksi sebesar 1.498 Yard. Dalam mengantisipasi terjadinya keterlambatan pengiriman bahan baku yang dilakukan oleh pemasok, maka berdasarkan metode EOQ, CV Syahdika harus melakukan titik pemesanan kembali (Re Order Point ketika persediaan bahan baku berada pada jumlah sebesar 1.420 Yard.

\section{REFERENSI}

Abdul H, Albasit Q. 2019. Penentuan Jumlah Produksi Produk Sofa Pada Ikm Noni Meubel Di Banjarsari Dengan Metode Linear Programming, Vol 6 No.1: 51-66, Unigal,
Penentuan Jumlah Produksi Produk Sofa Pada Ikm Noni Meubel Di Banjarsari Dengan Metode Linear Programming | Qodir | (Unigal.Ac.Id).

Batennia K, Suhardi B, Setya F, Hastuti P. 2019. Perencanaan Produksi Pada Seksi Painting Plastic Di Pt . Abc. In: Seminar Dan Konferensi Nasional Idec. Surakarta, P 2-3, Prosiding 2019 - 8th Idec (Uns.Ac.Id).

Nanda Fs. 2015. Pengendalian Persediaan Bahan Baku Dengan. 2: 1-11, Http://Lib.Unnes.Ac.Id/37996/1/7311414062. Pdf .

Palupi Pm, Korawijayanti L, Handoyono R, Semarang Pn. 2018. Penerapan Metode Economic Order Quantity ( Eoq ) Untuk Meningkatkan Efisiensi Biaya Persediaan Bahan Baku ( Studi Kasus Pada Pt Nusamulti Centralestari ). Prossiding Unimus 1: 426-435, Penerapan Metode Economic Order Quantity (Eoq) Untuk Meningkatkan Efisiensi Biaya Persediaan Bahan Baku (Studi Kasus Pada Pt Nusamulti Centralestari) | Palupi | Prosiding Seminar Nasional Unimus.

Sejati M, Singaraja Di, Farhana Cd, Putu G, Jana A, Suwendra I. 2016. Penjualan Terhadap Profitabilitas Pada Pt Ambara. 4: 1-10 Https://Ejournal.Undiksha.Ac.Id/Index.Php/Jm i/Article/View.

Simbar1 M, Katiandagho2 Tm, Lolowang2 Tf, Baroleh2 J. 2014. Jurnal Ilmiah, Oktober 2014.

Umami Dm, Rakhmawati R, Teknologi J, Pertanian I, Pertanian F, Madura Ut, Raya J, Bangkalan T. 2018. Analisis Efisiensi Biaya Persediaan Menggunakan Metode Eoq ( Economic Order Quantity ) Pada Pt. Xyz. Jurnal Agroteknologi Vol 12 No. Https://Jurnal.Unej.Ac.Id/Index.Php/Jagt/Artic le/View/8100. 